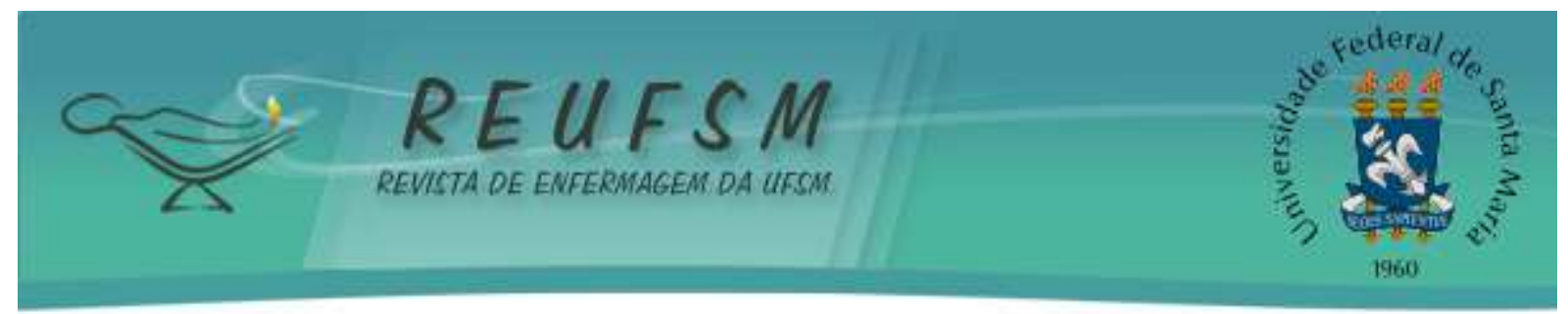

\title{
CONHECIMENTO DO ENFERMEIRO SOBRE A IMPORTÂNCIA E \\ OPERACIONALIZAÇÃO DO PROGRAMA NACIONAL DE TRIAGEM \\ NEONATAL
}

ARTIGO ORIGINAL

NURSE'S KNOWLEDGE ABOUT THE IMPORTANCE AND OPERATIONALIZATION
OF THE NATIONAL NEONATAL TRIAGE PROGRAM

\author{
CONOCIMIENTO DEL ENFERMERO SOBRE LA IMPORTANCIA Y LA \\ OPERACIONALIZACIÓN DEL PROGRAMA NACIONAL DE CLASIFICACIÓN \\ NEONATAL
}

\author{
Ana Cláudia Batistti ${ }^{1}$ \\ Angélica Pereira Borges ${ }^{2}$ \\ Grasiele Cristina Lucietto ${ }^{3}$ \\ Thalise Yuri Hattori ${ }^{4}$ \\ Vagner Ferreira do Nascimento ${ }^{5}$ \\ Juliana Fernandes Cabral ${ }^{6}$
}

Doi: $10.5902 / 2179769228030$

RESUMO: Objetivo: descrever o conhecimento do enfermeiro sobre a importância e operacionalização do Programa Nacional de Triagem Neonatal (PNTN). Método: estudo de abordagem qualitativa, do tipo descritivo, realizado com dez enfermeiros em um município do Mato Grosso, no período de agosto e setembro de 2016. Os dados foram coletados por meio de entrevista semiestruturada, e após foram submetidos à análise de conteúdo do tipo temática. Resultados: a simplificação das respostas referentes à Triagem Neonatal (TN) demonstraram certa insegurança em sua operacionalização, embasamento teórico superficial e fragmentado por parte dos participantes em retratar o PNTN. Considerações finais: verificou-se que os participantes possuíam conhecimentos sobre $\mathrm{TN}$, porém não os apresentavam de forma completa e concisa de acordo com a PNTN, o que remete a falta de programas de educação permanente e motivação para buscar mudanças.

Descritores: Enfermagem; Triagem neonatal; Saúde da criança

ABSTRACT: Aim: to describe nurses' knowledge about the importance and operationalization of the National Neonatal Triage Program (NNTP). Method: a qualitative, descriptive study carried out with ten nurses in a municipality of Mato Grosso, in the period

\footnotetext{
${ }^{1}$ Enfermeira. Graduada em Enfermagem pela Universidade do Estado de Mato Grosso. Cuiabá, Mato Grosso, Brasil. E-mail: annaclaudia13@hotmail.com

2 Enfermeira. Mestre em Enfermagem. Docente Assistente do Curso de Graduação em Enfermagem da UNEMAT - Campus de Tangará da Serra. Mato Grosso, Brasil. E-mail: angelica.borges@gmail.com

${ }^{3}$ Enfermeira. Mestre em Enfermagem. Docente Assistente do Curso de Graduação em Enfermagem da UNEMAT - Campus de Tangará da Serra. Mato Grosso, Brasil. E-mail: gralucietto@ gmail.com

${ }^{4}$ Enfermeira. Mestre em Ciências da Saúde. Docente Assistente do Curso de Graduação em Enfermagem da UNEMAT - Campus de Tangará da serra. Mato Grosso, Brasil. E-mail: thalisehattori@ gmail.com

${ }^{5}$ Enfermeiro. Mestre Profissional em Terapia Intensiva. Docente Assistente do Curso de Graduação em Enfermagem da UNEMAT - Campus de Tangará da Serra. Mato Grosso, Brasil. E-mail: vagnerschon@hotmail.com

${ }^{6}$ Enfermeira. Mestre em Saúde Coletiva. Docente Assistente do Curso de Graduação em Enfermagem da UNEMAT - Campus de Tangará da Serra. Mato Grosso, Brasil. E-mail: julianacabral@ unemat.br
} 


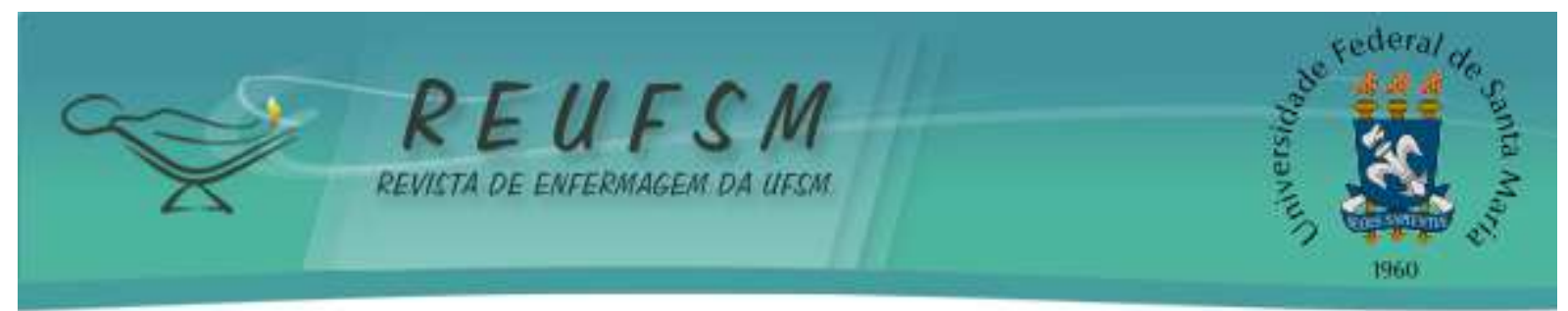

of August and September of 2016. The data was collected through a semi-structured interview, and afterwards they were submitted to a thematic analysis. Results: the simplification of the responses regarding the Neonatal Triage (NT) showed some insecurity in its operationalization, superficial and fragmented theoretical basis by the participants in portraying the NNTP. Final considerations: it was verified that the participants knew about NT, but did not present them in a complete and concise manner according to the NNTP, which refers to the lack of permanent education programs and motivation to seek changes.

Descriptors: Nursing; Neonatal triage; Child health

RESUMEN: Objetivo: describir el conocimiento del enfermero sobre la importancia y el funcionamiento del Programa Nacional de Clasificación Neonatal (PNTN). Método: estudio cualitativo, descriptivo, realizado con diez enfermeros en un municipio de Mato Grosso, en el período de agosto a septiembre de 2016. Los datos fueron recolectados por medio de entrevista semiestructurada, y analizados a partir del análisis de contenido del tipo temático. Resultados: en el análisis de las respuestas sobre la Clasificación Neonatal se identificó que hay inseguridad con relación operacionalización y base teórica superficial y fragmentada cuando los participantes en retratan el PNTN. Consideraciones finales: se observó que los participantes poseían conocimiento de clasificación neonatal, pero esa no está totalmente concisa y de acuerdo con el PNTN, lo que evidencia la falta de programas de educación continuada y de motivación para buscar cambios.

Descriptores: Enfermería; Clasificación neonatal; Salud del niño

\section{INTRODUÇÃO}

A triagem neonatal (TN) biológica popularmente conhecida como "teste do pezinho", tem como objetivo diagnosticar determinadas doenças entre 0-28 dias de vida. Originou-se no final da década de 1950 nos Estados Unidos, a qual visava a prevenção de doenças mentais em recém-nascidos $(\mathrm{RN})$. Desde então, desenvolve-se por meio de métodos mais eficazes de detecção de doenças metabólicas infecciosas e genéticas. ${ }^{1}$

No Brasil, foi incorporada ao Sistema Único de Saúde (SUS) em 1992 pela Portaria GM/MS n. ${ }^{\circ} 22$, tornando-se obrigatória, a sua realização, em todos os RN vivos. Entretanto, somente em 2001, foi criado o Programa Nacional de Triagem Neonatal (PNTN), com o intuito de conferir o rastreamento a toda população de recém-nascidos. ${ }^{1}$

Após a conclusão da Consulta Pública n ${ }^{\circ}$ 18, de 20 de setembro de 2013, o Ministério da Saúde juntamente com a Comissão Intergestores Tripartite (CIT) avaliaram a reformulação do PNTN para a inclusão das triagens clínicas: Triagem Neonatal Ocular, Teste do ReflexoVermelho, Triagem Neonatal Auditiva, e Triagem da Cardiopatia Congênita, conhecidos respectivamente como "teste do olhinho", "teste da orelhinha" e "teste do coraçãozinho". Porém, diante das mudanças de gestão ocorridas no âmbito ministerial foram desencadeados 


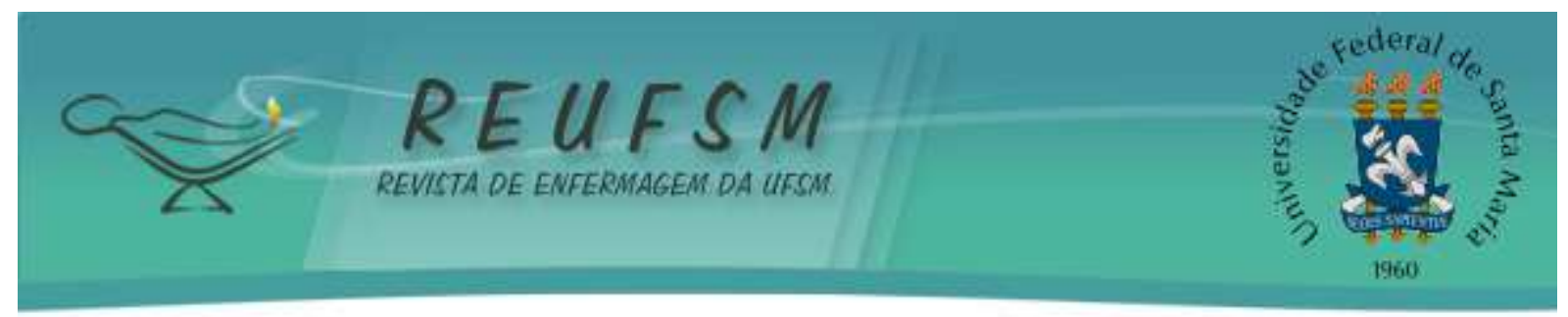

novos ajustes da proposta anteriormente apresentada, protelando sua publicação. Em Mato Grosso, desde outubro de 2002, o Hospital Universitário Júlio Müller (HUJM) da Universidade Federal de Mato Grosso (UFMT) é o serviço de referência no Estado em TN. ${ }^{2}$

Para garantir a cobertura, é necessário o envolvimento de pais/mães por meio de ações educativas, a fim de avalizar a adesão ao programa e consequentemente, a redução da morbimortalidade infantil. ${ }^{3}$ Neste cenário, o enfermeiro enquanto profissional inserido na atenção primária à saúde, torna-se responsável pela promoção da saúde, bem como a realização da TN, pois consegue problematizar com a gestante para a finalidade do teste, seus benefícios, o processo e o período de coleta. ${ }^{4}$

Apesar da técnica de coleta do exame estar descrita nos manuais ministeriais e os profissionais de enfermagem receberem constantes capacitações, identifica-se na literatura alguns erros procedimentais referentes à coleta, sendo as principais falhas: hemólise, insuficiência ou excesso de sangue, ressecamento, envelhecimento das amostras e armazenamento de forma errônea, que acarretam em resultados alterados e insatisfatórios. ${ }^{4}$

Esta realidade inviabiliza e compromete a qualidade da $\mathrm{TN}$, pois provocam atrasos na identificação das crianças possivelmente com alguma doença, já que necessitam de uma recoleta, podendo ainda haver dificuldades na localização da mãe e bebê. Sabe-se que os registros dos resultados e informações ainda são realizados manualmente e de forma descentralizada. Portanto, faz com que dados importantes da saúde de uma determinada população sejam perdidos e políticas voltadas a esses pacientes deixem de ser aplicadas. ${ }^{5}$

Neste sentido, a perda de um caso positivo, representa o não acompanhamento de uma criança que nasceu sem manifestações clínicas de alguma doença. Mesmo sem a possibilidade de cura, existem alternativas para evitar o surgimento do quadro clínico e permite uma boa qualidade de vida. $^{3}$

Faz-se necessário identificar as principais dificuldades que os profissionais de enfermagem apresentam durante as diversas fases da $\mathrm{TN}$ a fim de contribuir com a melhora da qualidade da assistência. Portanto este estudo apresentou como questão: qual o conhecimento do enfermeiro sobre a importância e operacionalização do PNTN?

Considerando a relevância do enfermeiro enquanto profissional inserido na atenção primária e responsável pelas ações de promoção da saúde, dentre elas as que envolvem a TN, justifica-se a 


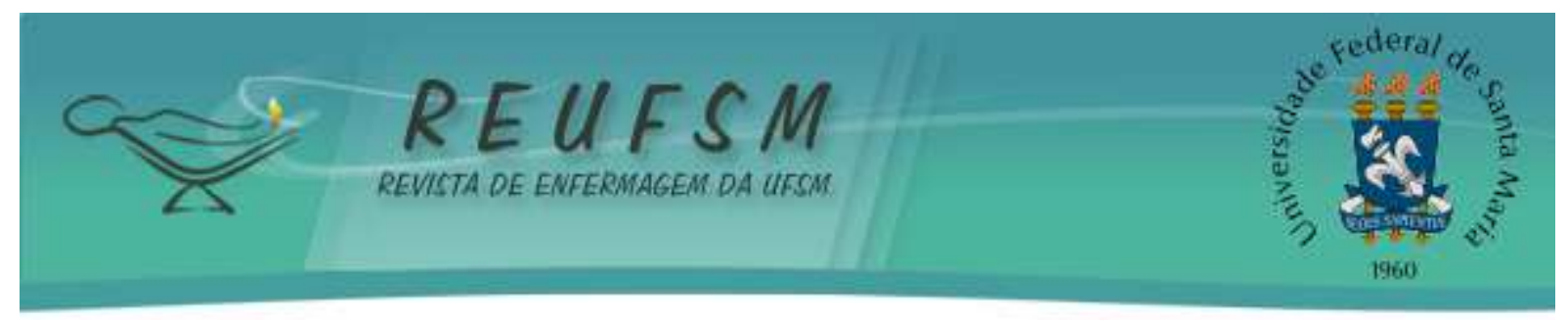

realização desta pesquisa, tendo em vista que o PNTN enfatiza a necessidade da abordagem sobre a importância do exame e demais orientações pelos profissionais de enfermagem.

Em vista disso, espera-se que com os resultados obtidos, seja possível propor intervenções que minimizem falhas e que contribuam para uma exequibilidade do processo de trabalho de maneira satisfatória. Desta forma, o objetivo foi descrever o conhecimento do enfermeiro sobre a importância e operacionalização do PNTN.

\section{MÉTODO}

Trata-se de um estudo de abordagem qualitativa, do tipo descritivo, realizado durante os meses de agosto e setembro de 2016. Os participantes da pesquisa foram enfermeiros responsáveis pelas respectivas Unidades de Estratégias de Saúde da Família (ESF) de Tangará da Serra, localizado na região sudoeste do Estado de Mato Grosso. O município possui 25 ESF e 20 enfermeiros atuantes neste cenário.

Os critérios adotados para inclusão foram: tempo de atuação em ESF urbanas igual ou superior a seis meses. Justifica-se esse critério uma vez que na zona rural do município não é realizada a TN devido à inexistência de ESF nestas localidades, sendo assim os recémnascidos são encaminhados até a área urbana. Quanto ao tempo inferior a seis meses de atuação profissional, impossibilita o enfermeiro de conhecer e operacionalizar o PNTN na área adscrita. Foram excluídos aqueles que se encontravam em período de licença maternidade ou férias. A pesquisa abrangeu o total de dez participantes, sendo cada indivíduo responsável por uma respectiva unidade de saúde.

Os dados foram coletados de acordo com a disponibilidade e concessão dos enfermeiros por meio do Termo de Consentimento Livre e Esclarecido (TCLE). A técnica utilizada foi a entrevista semiestruturada individual contendo perguntas abertas e fechadas, estas que versavam sobre questões pessoais e qualificações acerca da TN foram realizadas por um único entrevistador, uma vez que essa abordagem permite que o mesmo se coloque o mais próximo possível da perspectiva do entrevistado, e seguiu um roteiro de perguntas.

Com vistas à privacidade dos participantes, a coleta de dados foi realizada nos consultórios das unidades, respeitando a disponibilidade de cada profissional, capturadas por um gravador de áudio e, posteriormente, transcritas na íntegra com duração aproximada de 35 minutos. 


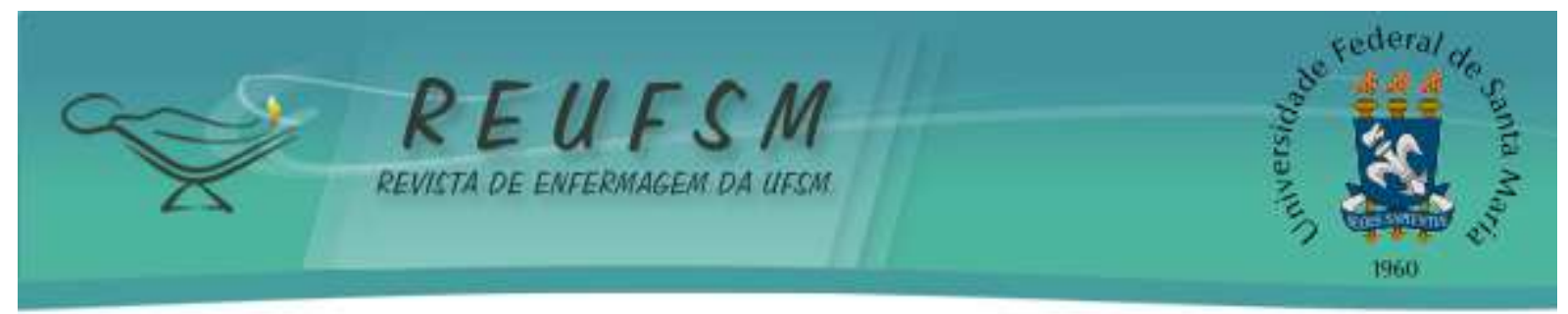

Para a organização dos dados foi adotada a codificação alfanumérica, sendo a sigla ENF para enfermeiro e a numeração de acordo com a sequência das entrevistas, garantindo o anonimato destes. A análise foi realizada progressiva e simultaneamente à sua coleta e quando o material empírico não contribuiu mais de forma significativa, o critério de saturação norteou a definição do número de participantes, sendo empregada a técnica de análise de conteúdo do tipo temática. A análise de conteúdo do tipo temática divide-se em três etapas: Pré-Análise, Exploração do Material e Tratamento dos Resultados Obtidos e Interpretação. ${ }^{6}$

A Pré-Análise incide na escolha dos dados a serem analisados e faz-se então a retomada do objeto, dos objetivos, dos pressupostos e fundamentos e se necessário, uma reformulação dos mesmos conforme os dados analisados. A fase de exploração do material propõe-se alcançar a compreensão dos dados obtidos, a separação das ideias, frases e parágrafos nos quais estão contidos as convergências e divergências dos participantes em relação a temática do estudo, realiza-se a associação dos dados, escolhendo as categorias teóricas ou baseadas em experiências, responsáveis pela especificidade dos temas. Na terceira e última fase o tratamento dos resultados obtidos e interpretação, trabalha-se os dados em sua forma bruta, permitindo evidenciar as informações obtidas. ${ }^{6}$

Este estudo foi aprovado pelo Comitê de Ética em Pesquisa da Universidade do Estado de Mato Grosso com o Parecer n ${ }^{\circ}$ 1.509.444/2016, em 20 de abril de 2016, atendendo todas as fases da Resolução n 466, de 12 de dezembro de 2012.

\section{RESULTADOS E DISCUSSÃO}

Participaram desta pesquisa dez enfermeiros na faixa etária entre 24-44 anos. Cinco especialistas em saúde da família, dois em obstetrícia, um em auditoria, um em gestão pública, e um mestre em Enfermagem. O tempo de atuação profissional variou entre um e onze anos.

A partir dos resultados obtidos, identificaram-se duas categorias, sendo que a primeira intitulada de Conhecimento do enfermeiro sobre a TN, expressa a percepção dos enfermeiros sobre o PNTN, quantas e quais as doenças detectadas, o período considerado ideal para realização do teste, o porquê de sua existência e quais as orientações repassadas para a mãe durante o pré-natal referente ao teste do pezinho. A segunda categoria denominou-se Operacionalização da coleta do teste que aborda quem é o responsável pela realização do teste, as dificuldades encontradas durante a coleta, se houve pedidos de recoletas referentes a 


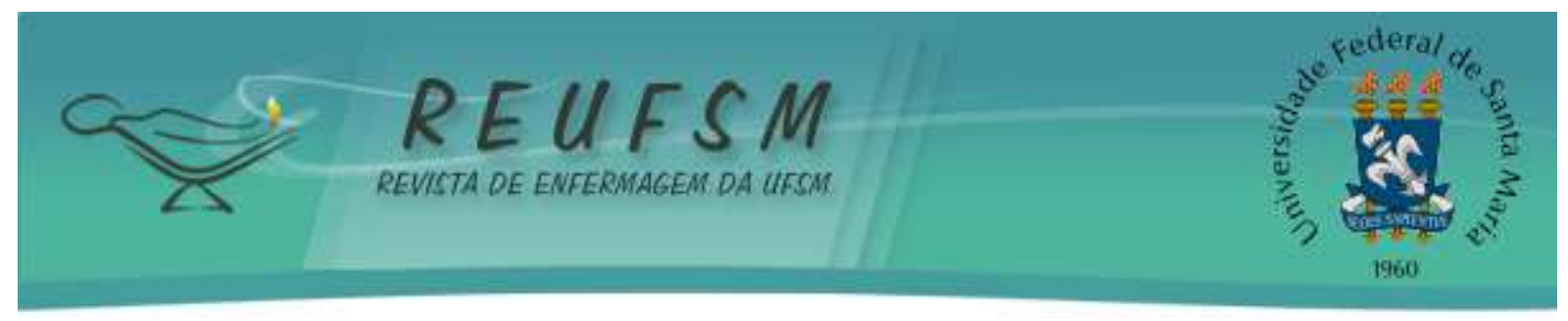

erros no processo e quais foram esses erros e de que modo é realizado o trabalho de busca ativa da mãe/pai com a chegada dos resultados.

\section{Conhecimento do enfermeiro sobre a triagem neonatal}

Dentre os dez enfermeiros entrevistados, percebeu-se que, apesar do tempo de formação e atuação profissional, não souberam responder corretamente quando indagados sobre a definição da TN. Isso remete a conhecimento fragmentado e reduzido, visto que todos a conceituaram como um método de detecção precoce de doenças que poderão futuramente causar sequelas às crianças, conforme o recorte das seguintes entrevistas:

TN é o exame que a gente faz para detectar precocemente algumas doenças para o bebê que futuramente pode causar alguma sequela, algum mal para ele. (ENF 01)

Então é conseguir verificar algumas doenças que podem trazer sequelas por um diagnóstico tardio no bebê ainda no primeiro mês de vida. (ENF 03)

A TN busca realizar o rastreamento de $100 \%$ dos nascidos vivos, pois engloba várias etapas como: a realização do exame laboratorial, a busca ativa dos casos suspeitos, a confirmação diagnóstica, o tratamento e o acompanhamento especializado quando necessário. ${ }^{1}$ Ao aplicar o significado da TN, identifica-se que consiste em um método de rastreamento que permite fazer o diagnóstico de doenças metabólicas, enzimáticas, endocrinológicas e genéticas no período neonatal, a fim de intervir no curso da doença, pois, desta forma, há a instituição de tratamento precoce específico e adequado, contribuindo para a diminuição ou eliminação das sequelas associadas a cada doença e, consequentemente, possibilita uma maior longevidade destes indivíduos. ${ }^{7}$

Nesse aspecto, percebe-se que os enfermeiros apresentaram dificuldades em abordar sobre a TN e sua finalidade, conceituando-a por meio de uma abordagem simples e reducionista com limitações em visualizar que se trata de uma estratégia muito além de somente oferecer detecção e tratamento de doenças.

É importante salientar que pelo fato da TN ser conhecida popularmente como "teste do pezinho", considera-se apenas a impressão plantar do bebê, o que denota déficit de conhecimento por parte de muitas mães e até mesmo dos profissionais da saúde. ${ }^{8}$ Desse modo, é preciso considerar que o enfermeiro esteja consciente e sensibilizado quanto a 


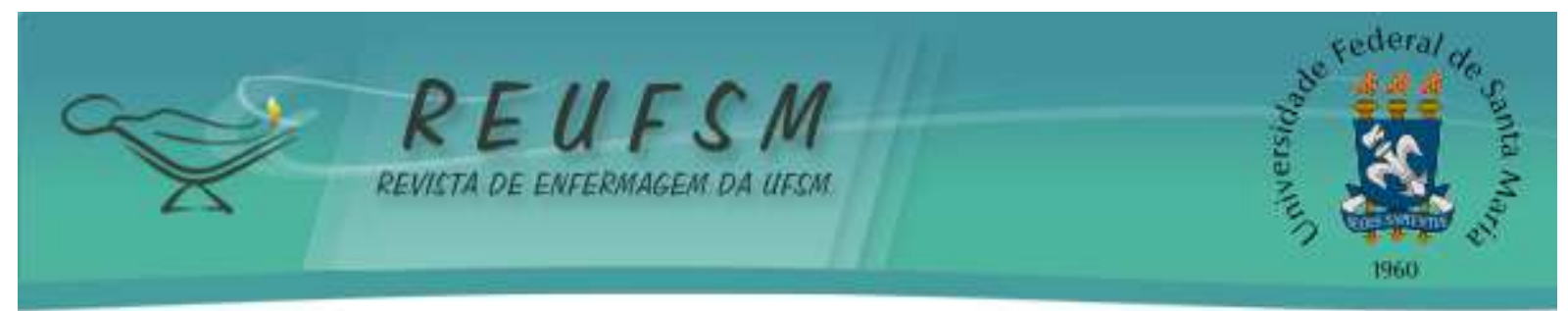

necessidade de aperfeiçoamento periódico por meio de educação permanente em saúde, pois o aprimoramento do conhecimento técnico-científico é fundamental para a qualificação do seu processo de trabalho e, assim, poder orientar pais e/ou responsáveis a considerarem o exame como algo indispensável ao crescimento e desenvolvimento do recém-nascido. ${ }^{9}$

Sobre o período considerado ideal para a realização da coleta da amostra de sangue, houve divergência em relação às respostas, o que demonstra fragilidades quanto à orientação apropriada.

Então, o que é preconizado pelo laboratório que é mandado as nossas amostras que a gente segue, é aquele que o período ideal seria do $5^{\circ}$ ao $7^{\circ}$ dias de vida, porém a gente colhe até os 30 dias. (ENF 03)

É no formulário do teste do pezinho eles falam para gente coletar do $3^{\circ}$ ao $7^{\circ}$ dia, aqui na unidade como orientação da vigilância epidemiológica a gente gosta de coletar do $5^{\circ}$ ao $7^{\circ}$. (ENF 08)

O período ideal para a coleta do teste consiste entre o terceiro e quinto dia de vida, sendo possível sua realização até o $28^{\circ}$ dia. ${ }^{1}$ Apenas dois participantes responderam corretamente sobre esta questão, o que reforça a pouca compreensão acerca da temática. Ao serem questionados sobre o estabelecimento de um intervalo preconizado, identificou-se insegurança nas respostas. Dentre o total de enfermeiros, quatro responderam que este ínterim existe, pois traz uma maior fidelidade ao teste, três responderam que é porque o metabolismo do bebê funciona adequadamente, um referiu que é ideal para acompanhamento e tratamento do recém-nascido e dois relatam não ter conhecimento sobre o motivo.

É o período que você identifica $e$ você teria um tempo de acompanhamento e tratamento dessa criança, quanto mais rápido você identificar mais rápido você poderá tratar e evitar sequelas ou problemas mais graves. (ENF 06)

Na verdade no curso eles tinham falado que é quando a criança, ela, eu não lembro [...] agora não vou saber te explicar. (ENF 09)

Respeitar o período neonatal para realizar o Teste do Pezinho é determinante para a instalação de tratamento específico e adequado a fim de diminuir ou eliminar sequelas de cada doença associada garantindo uma melhor qualidade de vida às crianças. ${ }^{10} \mathrm{~A}$ coleta é preconizada a partir do terceiro dia de vida, pois bebês com menos de 48 horas de nascimento ainda não fizeram a ingesta proteica suficiente para detectar de forma segura a fenilcetonúria, podendo ocasionar um resultado falso positivo. ${ }^{1}$ 


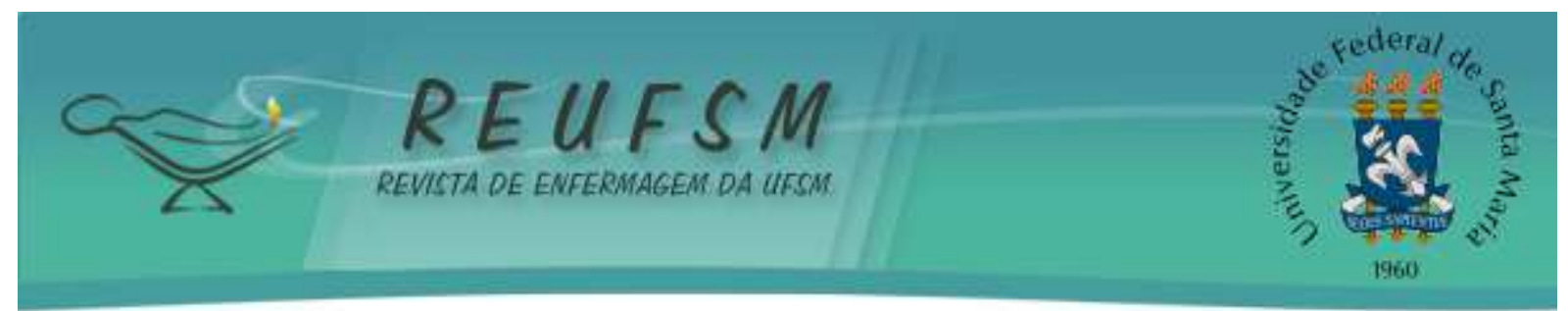

É importante salientar que o Teste do Pezinho é um exame somente de triagem, ou seja, um resultado alterado não significa um diagnóstico confirmatório de qualquer doença detectada pelo teste, necessitando neste caso, de exames confirmatórios, por exemplo, no caso da fibrose cística, o teste do pezinho detecta, mas somente o teste do suor confirma o diagnóstico da doença, por isso a necessidade da realização do teste no período correto, a fim de garantir tratamento precoce e adequado para os casos com diagnósticos definitivos. ${ }^{10-11}$

Quando indagadas sobre a quantidade de doenças rastreadas pelo PNTN por meio do teste, quatro participantes souberam apontar ao menos quatro das doenças, como se observa nos relatos:

Olha, nos laboratórios particulares são várias, no SUS as que eu lembro é fibrose cística, é a Fenilcetonúria, anemia falciforme e da tireoide. (ENF 01)

Eram cinco, acho que agora tem seis, Fibrose cística, Fenilcetonúria, hipotireoidismo congênito, anemia falciforme tem uma que é de um hormônio, mas agora não me recordo, estas são que eu lembro no momento. (ENF 03)

A TN é o maior programa de saúde pública preventiva no mundo. No Brasil, a sua implementação iniciou com o rastreamento de duas patologias e se deu em fases (I, II e III) de acordo com a organização e cobertura dos Estados. Em 2012 houve a expansão para a fase IV e a inclusão de mais duas doenças, totalizando o rastreamento de seis doenças pelo PNTN, ${ }^{11}$ no entanto, testes ampliados podem detectar até 46 patologias capazes de comprometer o sistema neuropsicomotor da criança. ${ }^{10}$

O estado de Mato Grosso está habilitado na Fase IV, que abrange a triagem da fenilcetonúria e outras hiperfenilalaninemias, hipotireoidismo congênito, doença falciforme e outas hemoglobinopatias, fibrose cística, deficiência de biotinidase e hiperplasia adrenal congênita. $^{2}$ Diante dos relatos se percebeu a carência do embasamento teórico e da atualização de conhecimento por parte dos enfermeiros, pois algumas respostas não condizem ao que é preconizado pelo Manual de Normas Técnicas do PNTN. ${ }^{1}$

No que se referem às orientações realizadas pelos enfermeiros com pais/mães, acerca da TN, identificou-se que as informações são fornecidas no início do pré-natal, sendo que a maioria dos participantes realizam somente a primeira consulta de enfermagem e as demais são realizadas pelo médico. Desta forma, o enfermeiro utiliza outros momentos para reforçar essas informações, tais como: coleta de exames, imunização, sala de espera e visitas domiciliares. 


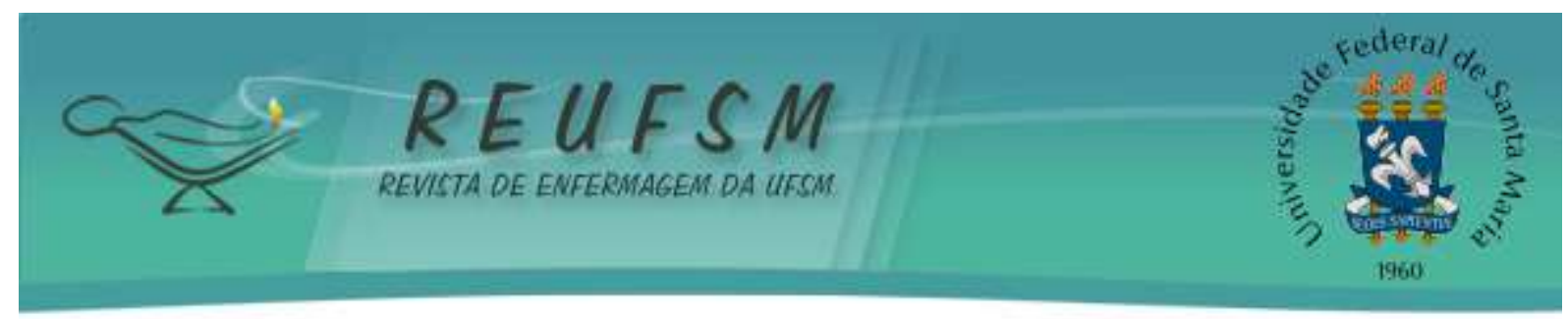

Então a gente faz quando elas [gestantes] vêm pra tomar as vacinas, sempre estamos falando e reforçando. (ENF 01)

Na primeira consulta de pré-natal a gestante não vai se atentar a isso, ela não vai lembrar então essa orientação na verdade é no puerpério. (ENF 05)

O enfermeiro deve utilizar de estratégias de ensino-aprendizagem que facilitem o entendimento das mães/familiares sobre todo o processo da $\mathrm{TN}$, e considerar as particularidades de cada ser humano, seu contexto social, econômico. Além de abordar o sujeito de forma singular com orientações individualizadas que corrobore com as práticas de cuidar-educar da enfermagem a fim de colaborar com a construção de um indivíduo mais autônomo e construtor do seu próprio conhecimento. ${ }^{9-12}$

\section{Operacionalização da coleta do teste}

Antes do início do teste, é imprescindível que se realize o preenchimento das informações quanto a identificação do $\mathrm{RN}$ e da mãe constantes no formulário do cartão de coleta com letra legível. A documentação e registro da realização do teste possibilita a localização da família em casos de reconvocação para o exame. ${ }^{1}$

Posteriormente, realiza-se o preparo do material para colher o exame, em que são necessárias luvas de procedimento, gaze ou algodão seco, álcool a 70\%, lanceta apropriada, estante para a secagem da amostra e papel filtro, este deve se encontrar com a embalagem íntegra e com a data de validade em dia. ${ }^{4}$ Realiza-se então, a assepsia local no calcanhar do bebê com gaze ou algodão com álcool a 70\%, aguardar o local secar completamente. Com a lanceta, é feito um pequeno furo em uma das laterais da região plantar no calcanhar do $\mathrm{RN}$, com intuito de coletar algumas gotas de sangue para análise. É necessário deixar formar a primeira gota e desprezá-la, limpar com gaze estéril, para que qualquer resíduo de álcool seja eliminado e não interfira no resultado do exame, a partir daí, colhe-se o sangue/amostra. As amostras colhidas devem secar em temperatura ambiente de uma a três horas em posição horizontal, em local seco e protegido de luz. ${ }^{1}$

Os participantes que descreveram os conhecimentos procedimentais de forma correspondente ao que se aplica no Manual de Referência para o Estado de Mato Grosso do Hospital Universitário Júlio Muller ${ }^{4}$ foram categorizados como satisfatório. Aqueles que mencionaram informações importantes com relação às orientações para os acompanhantes, 


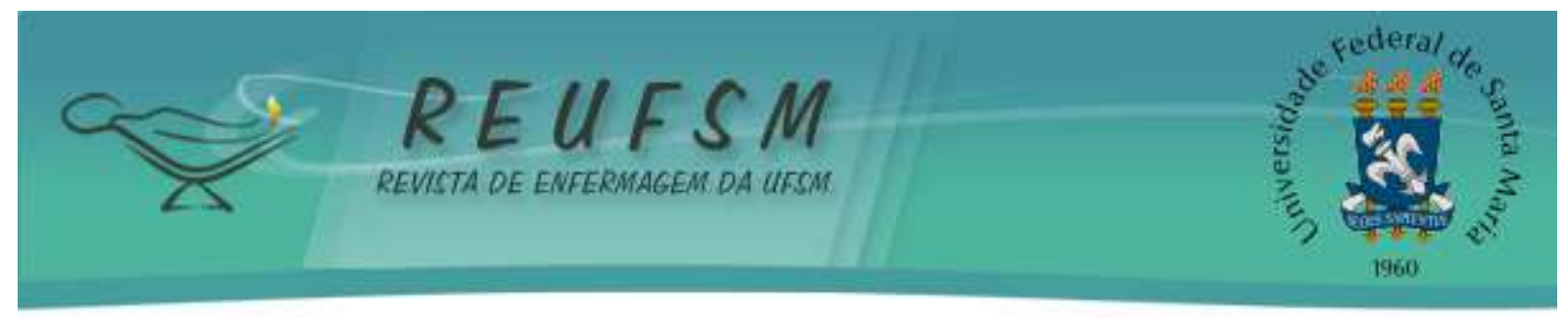

posicionamento da criança, assepsia, processo de coleta, preenchimento dos círculos, secagem e armazenagem das amostras coletadas de forma resumida e exígua foram catalogados como pouco satisfatórios. E por fim, as informações insuficientes e/ou incompletas foram classificadas como não satisfatório, sendo informações referentes somente ao preenchimento do cartão, processo de coleta da amostra, secagem e armazenagem dos filtros. Assim, os resultados evidenciaram que cinco enfermeiros foram classificados em satisfatório, três em pouco satisfatório e dois participantes em não satisfatório.

Constatou-se que somente metade dos entrevistados soube descrever o método correto da realização do teste, que corrobora com achados de outros estudos que evidenciaram a falta de conhecimento dos profissionais de enfermagem acerca da operacionalização do teste. ${ }^{11-13}$ Apesar do enfermeiro não realizar rotineiramente o exame, ele deve estar capacitado e atualizado para a realização de educação permanente com sua equipe e estar atento para possíveis erros que possam ocorrer durante o processo da coleta.

Quanto ao acolhimento, observou-se que sete dos participantes demonstraram preocupação em realizá-lo, de acolher o responsável juntamente com a criança momentos antes da realização do teste e fazer uso de estratégias de conscientização de modo individualizado. A Política Nacional de Humanização (PNH) define o termo "acolhimento" na saúde, como um conjunto de estratégias que visam a qualificação da escuta, para a melhora do estabelecimento de vínculos interprofissionais, que possibilite a formação de um elo entre usuários, trabalhadores e gestores e proporcione resolutividade dos serviços. ${ }^{14}$

Primeiro tem que ter o acolhimento, aquela conversa já com os pais, explicar quais são as patologias, se existe tratamento, se existe no caso alongamento de vida também. (ENF 04)

Nós recebemos essa mãe, explicamos para que serve este teste, o período que é pra ser entregue o resultado ou não, fazemos todas essas orientações prévias, quais são as doenças que elas detectam, a importância de fazer, de buscar. (ENF 02)

Quando indagados sobre a realização do teste, foi questionado quem seria o responsável por desempenhá-lo, verificou-se que seis enfermeiros realizam o procedimento de forma parcial juntamente com o técnico de enfermagem, três participantes afirmaram não realizar e apenas um dos participantes afirmou ser o responsável pela coleta das amostras na unidade em que atua. 


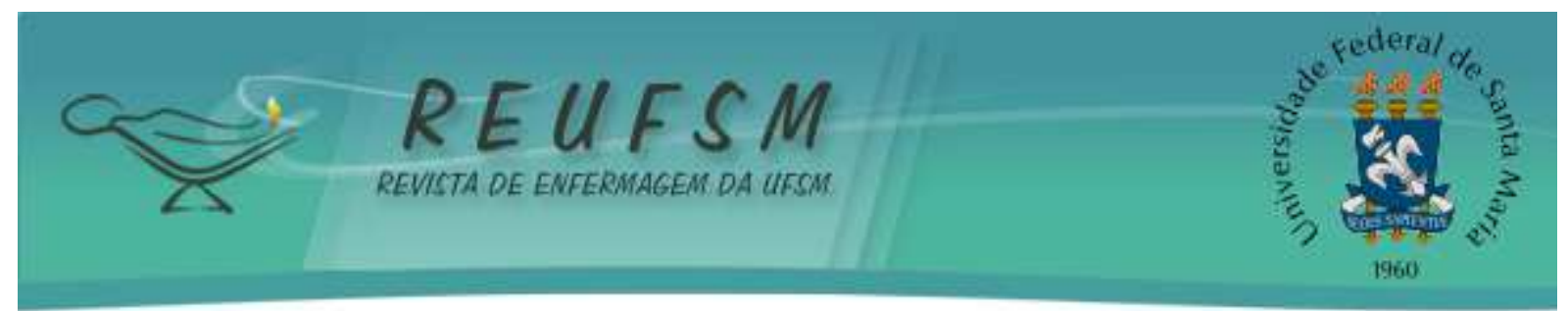

Os participantes mencionaram como empecilho para a execução do exame, a burocratização do processo de trabalho, evidenciado, principalmente pelo seu papel de gestor da unidade. A sobrecarga de trabalho afeta o enfermeiro que atua na ESF pela lógica de organização, na qual se avalia a produtividade e não a qualidade dos serviços prestados, com impactos no trabalho em equipe bem como no reconhecimento profissional. ${ }^{15}$

Aqui quem faz é o enfermeiro responsável, mas como acaba tendo muita parte burocrática e às vezes outros procedimentos quem acaba fazendo é o técnico. (ENF 09)

De acordo com a narrativa, observou-se dificuldade por parte dos enfermeiros em realizar o processo da coleta. Conforme a lei $\mathrm{n}^{\mathrm{o}} 5.905 / 73$ a execução do teste pode ser efetuada pelos profissionais de enfermagem em todas as suas categorias com supervisão constante do enfermeiro. No entanto, ressalta-se que para a sua realização, tanto enfermeiros, quanto técnicos e auxiliares de enfermagem necessitam de capacitação para execução de tal atividade. ${ }^{16}$

Em relação as principais complicações relatadas, identificou-se a dificuldade da coleta de amostra suficiente do sangue, falta de materiais específicos, e ainda problemas com relação aos pais/mães que não se mostram colaborativos no momento da realização do teste, como evidenciadas a seguir:

É alguma criança que a gente não consegue o "sanguinho" acho que a maior dificuldade é essa, e às vezes algum pai ou alguma mãe que não colabora. (ENF 01)

A única dificuldade são esses raros casos em que pai e mãe mesmo orientados têm um receio porque vai doer no bebê, $e$ às vezes a questão da lanceta quando você utiliza um material que não é próprio, vem a dificuldade, que o sangue que você coletaria com um furo adequado não é o mesmo quando você usa um material que não é o adequado. (ENF 03)

As principais dificuldades envolvidas na coleta do teste foram a quantidade insuficiente de sangue para o exame, em sua maioria pela falta de colaboração dos pais ou responsáveis pela criança. Dessa maneira, reitera-se a importância de orientar os pais a respeito do procedimento a ser executado, assim como sua finalidade e necessidade de retirada do sangue. ${ }^{1} \mathrm{O}$ desconhecimento, além de levar à falta de colaboração no momento do exame, pode contribuir para que muitos pais não levem seus bebês para a realização do teste ou para a recoleta. 


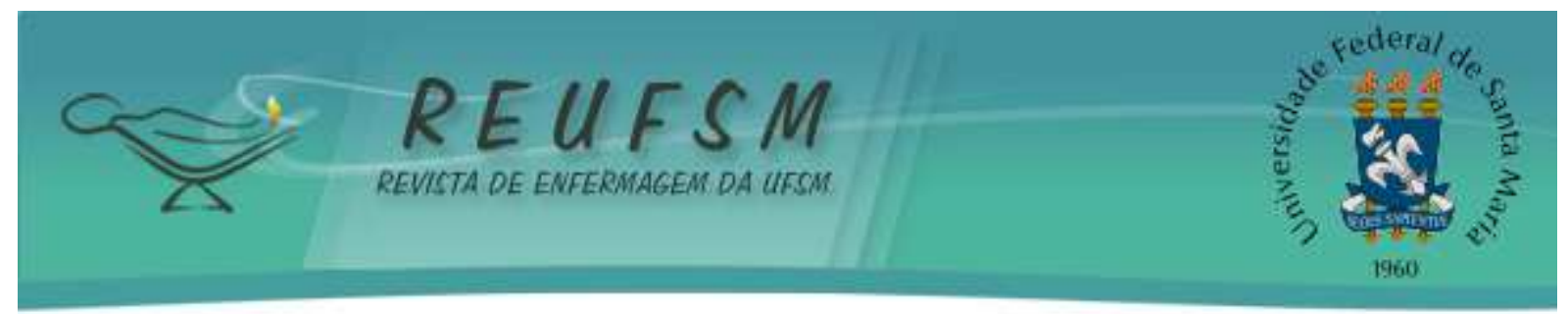

Estudos realizados no Rio Grande do Sul e Minas Gerais demonstraram que as puérperas gostariam de receber mais informações sobre o teste do pezinho, relacionadas com o motivo do mesmo, procedimento, doenças diagnosticadas, período, dentre outras. ${ }^{3-17}$

Outra dificuldade reportada por uma das enfermeiras é quanto a qualidade da coleta, especialmente no que diz respeito à quantidade de sangue captado, justificado pelo uso de material inadequado para a punção que deve ser realizada com lancetas apropriadas, autorretrateis para evitar acidentes com perfuro-cortantes, estéreis, descartáveis, com profundidade entre $1,8 \mathrm{~mm}$ e $2,00 \mathrm{~mm}$ e largura entre $1,5 \mathrm{~mm}$ e $2,00 \mathrm{~mm}$, atendendo às especificações da Norma Regulamentadora $n^{\circ} 32$ (Segurança e Saúde no Trabalho em Estabelecimentos de Assistência à Saúde, do Ministério do Trabalho). ${ }^{1}$

Quando indagados se já houve erros durante o processo de coleta e quais foram os motivos do pedido de recoleta, quatro participantes relataram sua ocorrência, sendo: preenchimento inadequado do campo de dados das informações do recém-nascido, acúmulo de gotas de sangue no mesmo círculo e causa desconhecida.

Ao analisar os dados obtidos, percebe-se que os erros ocorrem em forma de ciclo, pois se a coleta é realizada de modo fragmentado, os erros ocorrerão sem chances de mudança, o que resulta em uma recoleta do material. Em consequência disso, há atraso na identificação de possíveis doenças, desperdício de amostras, crianças que não retornam mais ao serviço de saúde, além de uma exposição maior do recém-nascido ao desconforto. Vivenciar a recoleta de material para realização da TN pode ocasionar danos físicos e emocionais para o bebê e sua família, visto que esta reconvocação pode gerar sentimento de insegurança, ansiedade, medo, desconforto e estresse aos mesmos. ${ }^{18}$

Dado o exposto, é primordial oportunizar educação permanente com a equipe de enfermagem responsável pela coleta da amostra, visto que erros são decorrentes da falha humana por desatenção e/ou falta de conhecimento, a existência de uma fragmentação na técnica pode refletir na qualidade dos serviços prestados. ${ }^{9-11-13}$

Quanto ao trabalho de busca ativa do pai/mãe e da criança no que se refere a entrega do resultado do exame, todos os participantes afirmaram realizar o processo, porém cada profissional desempenha essa atividade de forma diferenciada conforme a demanda de sua localidade. A maioria dos participantes realiza a busca ativa por meio dos agentes comunitários de saúde que informam a família sobre o resultado do exame. Houve ainda 


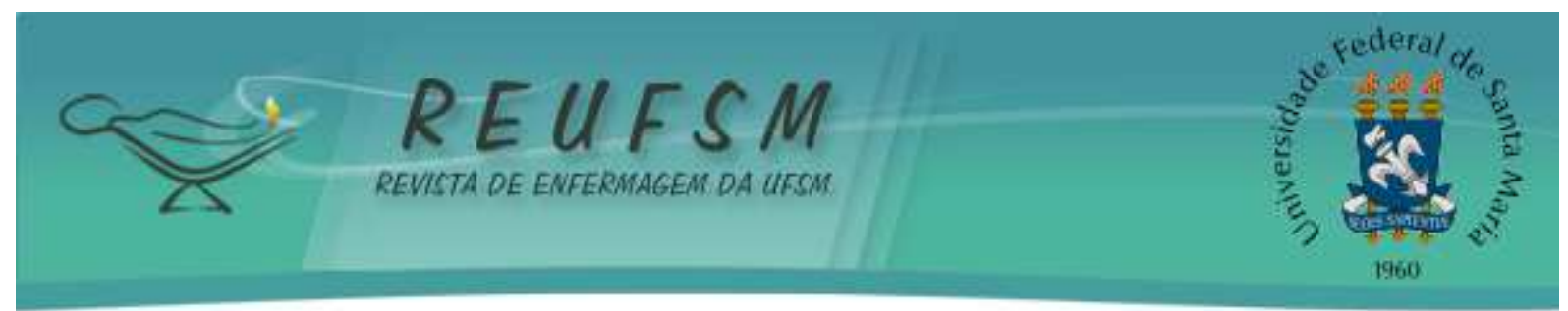

relatos de enfermeiros que entram em contato com a família somente se o resultado obtiver alguma alteração, do contrário, aguardam o retorno da mãe à unidade ou entram em contato por meio de ligações.

A gente tem acesso ao sistema, então liberou os exames, a gente imprime e daí pede para os agentes de saúde irem atrás. (ENF 01)

Os resultados que vêm alterados, reconvocados. Se tem alguma alteração esses nós vamos atrás, os que não vêm está tudo normal, esses daí a gente espera o procedimento normal, eles virem buscar. (ENF 10)

O trabalho de busca ativa é necessário, visto que se configura como uma ferramenta de identificação de casos positivos de possíveis doenças. Para que ocorra este processo de forma efetiva, deve-se haver atenção no momento do preenchimento da ficha de coleta, pois é nela que estarão contidas informações referentes à criança, e se houver casos de reconvocação tanto por resultados alterados para alguma doença, como por erros procedimentais, a busca da família será mais rápida e eficaz. ${ }^{19}$

Dentre as etapas da Triagem Neonatal, após o diagnóstico presuntivo e o diagnóstico definitivo ou de certeza, está a melhoria da efetividade do acesso ao tratamento e acompanhamento dos casos diagnosticados, por meio das ações operacionais para monitoramento e acompanhamento das crianças, que incluem a busca ativa para a recoleta, reteste, reavaliação, agendamento de consultas e acompanhamento de comparecimento. ${ }^{1}$

\section{CONSIDERAÇÕES FINAIS}

A partir dos resultados, verificou-se que os participantes possuem conhecimentos sobre TN, porém não os apresentam de forma completa e concisa de acordo com a PNTN, o que pode gerar insegurança à família, risco ao $\mathrm{RN}$, bem como não atingir toda finalidade do cuidado em enfermagem. O distanciamento desses profissionais do compromisso com o acompanhamento integral ao recém-nascido, delegado muitas vezes a outros profissionais, contribui para invisibilidade das ações de enfermagem em prol da prevenção de doenças e promoção da saúde dessa clientela.

Verificou-se que os participantes se esbarram em alguns obstáculos para a plena operacionalização da PNTN, em especial, na realização do teste do pezinho, pela dificuldade em gerenciar todas as atividades da unidade de saúde e ao mesmo tempo em possuir 


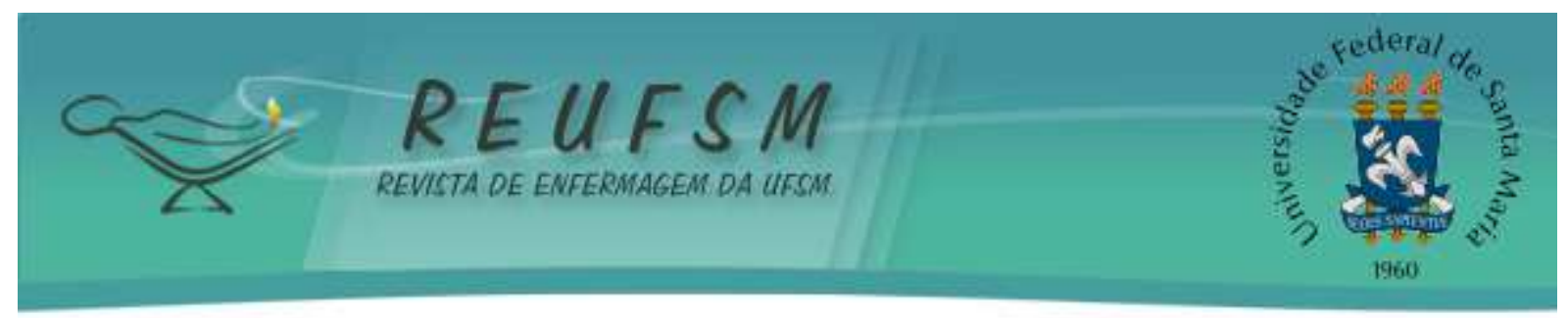

disponibilidade para realizar o procedimento por demanda espontânea, ou ainda, por enfrentarem cenários com recursos materiais nem sempre adequados e familiares pouco colaborativos no momento da assistência.

Além disso, os profissionais se apresentam pouco integrados à equipe, o que remete a falta de programas de educação permanente e motivação para buscar mudanças. Dessa forma, há que se rever o planejamento das ações em saúde desses serviços, de modo a definir prioridades e possibilidades para a efetivação do PNTN, como também propor um processo crítico e reflexivo aos profissionais no desenvolvimento de habilidades para melhoria da assistência à população infantil.

Outros estudos devem ser realizados, principalmente abordando as políticas públicas locais e a articulação com o PNTN, o que pode auxiliar na compreensão dos desafios que emergem no cotidiano assistencial e assim direcionar novas estratégias para ampliar a qualidade da assistência.

Destaca-se que o estudo apresenta como limitações, o fato de ser realizado apenas na perspectiva dos enfermeiros, tendo excluído os técnicos de enfermagem visto que em diversas unidades de saúde são eles que executam o procedimento e nesse contexto desenvolvem maior vínculo com a clientela, o que impossibilita a generalização dos achados.

\section{REFERÊNCIAS}

1. Brasil. Ministério da Saúde. Secretaria de Atenção à Saúde. Departamento de Atenção Especializada e Temática. Triagem neonatal biológica: manual técnico. $1^{\mathrm{a}}$ ed. Brasília: Ministério da Saúde; 2016.

2. Universidade do Estado de Mato Grosso (UFMT). Teste do pezinho chega à Fase IV. Notícias [Internet]. 2014 [acesso em 2016 out 16]. Disponível em: http://www.ufmt.br/ufmt/site/noticia/visualizar/17358/Cuiaba.

3. Al-Alam AC, Soares MC, Meincke SMK, Dilélio AS, Escobal APL. Entendimento das mães acerca da triagem neonatal: um estudo qualitativo. J Nurs Health [Internet]. 2012 [acesso em 2016 jul 18];1(2):75-81. Disponível em: https://periodicos.ufpel.edu.br/ojs2/index.php/enfermagem/article/view/3451.

4. Fundação Universidade Federal de Mato Grosso. Hospital universitário julio Muller. Serviço de Referência em Triagem Neonatal. Manual de procedimentos para postos de coleta do teste do pezinho. Cuiabá: UFMT; 2013.

5. Carvalho DCSN, Macêdo TCC, Moreno M, Figueiredo FWS, Sales IB, Christofolini J, et al. Evolução do Programa de Triagem Neonatal em hospital de referência no Ceará: 11 anos de observação. ABCS Health Sci [Internet]. 2017 [acesso em 2018 mar 10];42(3):143-6. Disponível em: https://www.portalnepas.org.br/abcshs/article/view/933. 


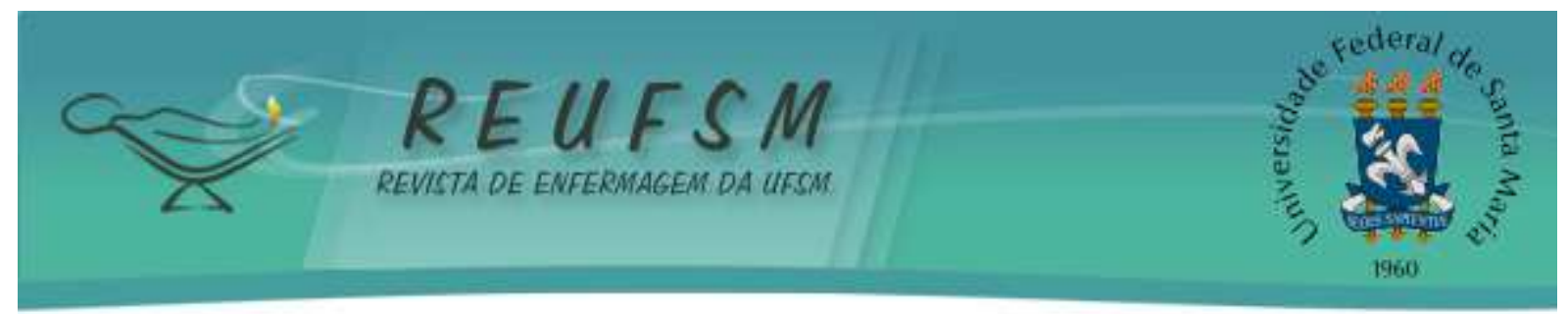

6. Minayo MCS. Pesquisa social: teoria, método e criatividade. Petrópolis: Vozes; 2012.

7. Delvivo EM, Nazareth JB, Salvador M, Salimena AM, Dias IMAV. Teste do pezinho: desvelando o conhecimento das mães sobre o exame. HU Revista [Internet]. 2012[acesso em 2016 jan-jun 01];38(1-2):91-6. Disponível em: https://hurevista.ufjf.emnuvens.com.br/hurevista/article/view/1944.

8. Abreu IS, Braguini WL. Triagem neonatal: o conhecimento materno em uma maternidade no interior do Paraná, Brasil. Rev Gaúcha Enferm [Internet]. 2011[acesso em 2018 mar 10]; 32(3):596-601. Disponível em: http://www.scielo.br/pdf/rgenf/v32n3/23.pdf.

9. Acosta DF, Strefling ISS, GomesVLO. Triagem neonatal: (re)pensando a prática de enfermagem. Rev Enferm UFPE [Internet]. 2013 [acesso em 2018 mar 10];7(2):572-8. Disponível

em:

https://periodicos.ufpe.br/revistas/revistaenfermagem/article/view/10269/10901.

10. Sociedade Brasileira de Triagem Neonatal (SBTN) [Internet]. [acesso em 2015 out 01]. Disponível em: http://www.sbtn.org.br.

11. Marqui ABT. Teste do Pezinho e o Papel da Enfermagem: uma reflexão. Rev Enferm Atenção à Saúde [Internet]. 2016 [acesso em $2016 \mathrm{dez}$ 12];5(2):96-103. Disponível em: http://seer.uftm.edu.br/revistaeletronica/index.php/enfer/article/view/1605/pdf.

12. Reis EFS, Partelli ANM. Teste do Pezinho: conhecimento e atitude dos profissionais de enfermagem. Rev Bras Pesq Saúde [Internet]. 2014 [acesso em 2016 set 13];16(1):25-33. Disponível em: http://periodicos.ufes.br/RBPS/article/view/8489.

13. Strefling ISS, Monfrim XM, Lunardi Filho WD, Carvalho KK, Azevedo ALS. Conhecimento sobre Triagem Neonatal e sua Operacionalização. Cogitare Enferm [Internet].2014 [acesso em 2016 ago 17];19(1):27-33. Disponível em: http://revistas.ufpr.br/cogitare/article/view/35928.

14. Pelisoli C, Sacco AM, Barbosa ET, Pereira CO, Cecconello AM. Acolhimento em saúde: uma revisão sistemática em periódicos brasileiros. Estud Psicol [Internet]. 2014 [acesso em 2016 jul 19];31(2):225-35. Disponível em: http://www.scielosp.org/scielo.php?script=sci_arttext\&pid=S0124-00642011000400015.

15. Lima FS, Amestoy SC, Jacondino MB, Trindade LL, Silva CN, Fuculo Junior PRB. Exercício da liderança do enfermeiro na estratégia saúde da família. Fundam Care [Internet]. 2016 [acesso em 2016 set 12];8(1):3893-906. Disponível em: http://pesquisa.bvsalud.org/portal/resource/pt/bde-27363.

16. Conselho Regional de Enfermagem do Rio Grande do Sul-RS (Coren-RS). Parecer Defisc $\mathrm{n}^{\circ} 8$ de 11 de maio de 2012. Realização do Teste do Pezinho por Profissionais de Enfermagem [Internet]. 2012 [acesso em 2016 jul 12]. Disponível em: https://www.portalcorenrs.gov.br/docs/Legislacoes/legislacao_59fcdf77d476530e093e57d6234b731d.pdf.

17. Arduinia GAO, Balarina MAS, Silva Greccoa RL, Marqu ABT. Conhecimento das puérperas sobre o teste do pezinho. Rev Paul Pediatr [Internet]. 2017 [acesso em 2018 mar 10];35(2):151-7. Disponível em: http://www.scielo.br/scielo.php?pid=S0103$05822017000200151 \&$ script=sci_abstract\&tlng=pt. 


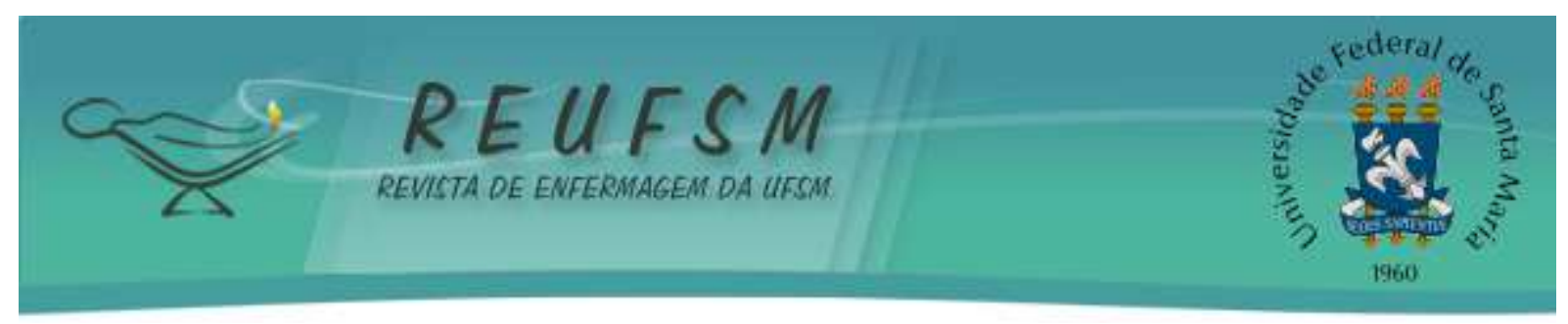

18. Pimente EDC, Luz GS, Schiavon GB, Pelloso SM, Carvalho MDB. Teste do Pezinho: A Humanização do Cuidado e do Profissional. REME-Rev Min Enferm [Internet]. 2010 [acesso em 2018 mar 10];14(1):25-8. Disponível em: http://www.reme.org.br/artigo/detalhes/83

19. Silva RMM, Lui AM, Correio TZHO, Arcoverde MAM, Meira MCR, Cardoso LL. Busca ativa de crianças com necessidades especiais de saúde na comunidade: relato de experiência. Rev Enferm UFSM [Internet]. 2015 [acesso em 2016 jul 18];5(1):178-85. Disponível em: https://periodicos.ufsm.br/reufsm/article/view/13024.

Data de submissão: 07/07/2017

Data de aceite: $23 / 04 / 2018$

Autor correspondente: Ana Cláudia Batistti

E-mail: annaclaudia13@ @otmail.com

Endereço: Rua Pimenta Bueno, N901/ Apt. 208, Bairro Dom Aquino, Cuiabá/MT

CEP: 78015-190 